\title{
Antioxidant therapy with Salvia miltiorrhiza decreases plasma endothelin-1 and thromboxane B2 after cardiopulmonary bypass in patients with congenital heart disease
}

\author{
Zhengyuan Xia, MD, MSc ${ }^{a, b}$ \\ Jiazhen $\mathrm{Gu}, \mathrm{MD}^{\mathrm{a}}$ \\ David M. Ansley, MD, FRCPC \\ Fang $\mathrm{Xia}, \mathrm{MD}^{\mathrm{a}}$ \\ Jinfu Yu, MD
}

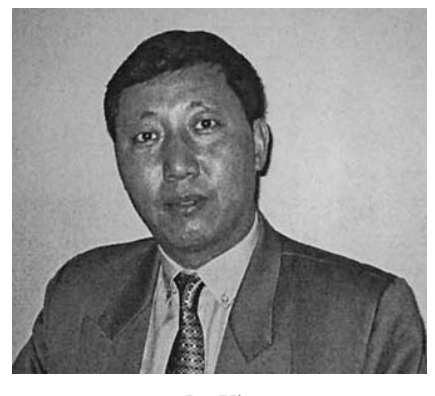

Dr Xia

From the Department of Anesthesiology, Affiliated Renmin Hospital, Wuhan University, ${ }^{a}$ Wuhan, PR China, and the Centre for Anesthesia and Analgesia, Department of Pharmacology and Therapeutics, Faculty of Medicine, ${ }^{\mathrm{b}}$ University of British Columbia, Vancouver, British Columbia, Canada.

This study was supported in part by an internal research grant (to Drs Gu and Xia) from the First Affiliated Hospital of Hubei Medical University (current name: Renmin Hospital, Wuhan University), Wuhan, PR China. Z. Xia is the recipient of a fellowship from the Centre for Anesthesia and Analgesia, Department of Pharmacology and Therapeutics, University of British Columbia, Canada.

Received for publication Sept 6, 2002; revisions requested Oct 16, 2002; revisions received Jan 2, 2003; accepted for publication March 25, 2003.

Address for reprints: Zhengyuan Xia, MD, Centre for Anesthesia and Analgesia, Department of Pharmacology and Therapeutics, Faculty of Medicine, The University of British Columbia, 2176 Health Sciences Mall, Vancouver, BC, Canada V6T 1Z3 (E-mail: xia@neuro.pharmacology.ubc.ca).

J Thorac Cardiovasc Surg 2003;126: 1404-10

Copyright $\odot 2003$ by The American Association for Thoracic Surgery

0022-5223/2003\$30.00+0

doi:10.1016/S0022-5223(03)00970-X
Objective: The endothelium-derived vasoconstrictor endothelin-1 is increased after cardiopulmonary bypass in children with congenital heart defects. This study determines whether antioxidant therapy with Salvia miltiorrhiza injection, an herb extract containing phenolic compounds, prevents the postoperative increase of endothelin-1. The relationship between endothelin-1 and the endothelium-derived prostacyclin (prostaglandin I2) and thromboxane A2 postoperatively is also investigated.

Methods: Twenty children with congenital heart defects and pulmonary hypertension were randomly assigned to group A (placebo control, $\mathrm{n}=10)$ or $\mathrm{B}(200 \mathrm{mg} / \mathrm{kg}$ Salvia miltiorrhiza intravenously after anesthesia induction and at the time of rewarming, respectively; $\mathrm{n}=10$ ) before cardiac surgery. Central venous blood samples were taken before operation $\left(\mathrm{T}_{0}\right), 10\left(\mathrm{~T}_{1}\right)$ and 30 minutes $\left(\mathrm{T}_{2}\right)$ after starting cardiopulmonary bypass, $10\left(\mathrm{~T}_{3}\right)$ and 30 minutes $\left(\mathrm{T}_{4}\right)$ after aortic declamping, and 30 minutes $\left(\mathrm{T}_{5}\right)$ and 24 hours $\left(\mathrm{T}_{6}\right)$ after termination of cardiopulmonary bypass. Plasma lipid peroxidation product malondialdehyde, myocardial specific creatine kinase-MB activity, thromboxane B2, and 6-keto-prostaglandin $\mathrm{F}_{1 \alpha}$ (stable metabolites of thromboxane A2 and prostaglandin I2) were measured.

Results: Malondialdehyde increased significantly at $\mathrm{T}_{1}$ in group A and remained significantly higher than in group B thereafter $(P<.05)$. Malondialdehyde in group $B$ did not significantly increase over time. At $T_{5}$, plasma creatine kinase-MB, thromboxane $\mathrm{B} 2$, and endothelin-1 in group $\mathrm{B}$ were lower than in group $\mathrm{A}(P<$ $.05)$; malondialdehyde correlated significantly with creatine kinase-MB $(r=0.71$, $P=.0005)$. At $\mathrm{T}_{6}$, endothelin-1 negatively correlated with the 6-keto-prostaglandin $\mathrm{F}_{1 \alpha} /$ thromboxane B2 ratio $(r=-0.64, P=.0025)$.

Conclusion: Antioxidant therapy reduces myocardial damage and attenuates postoperative vasoactive mediator imbalance.

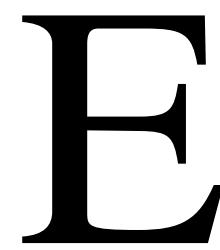
ndothelial regulation of local vascular tone is mediated by a variety of endothelium-derived relaxing and contracting factors such as nitric oxide (NO), prostaglandin (PG) I2, thromboxane (TX) A2, and endothelin (ET)-1. ${ }^{1}$ ET-1 is a potent vasoconstrictor known to reduce myocardial contractility and contribute to the progression of the heart failure process. ${ }^{2,3}$ The plasma level of ET-1 increases during cardiac operations requiring cardiopulmonary bypass (CPB).$^{4-7}$ A high plasma ET-1 level during the early postoperative period has been associated with prolonged 
pharmacologic management, longer intensive care unit stay, and complicated recovery. ${ }^{4,8}$

In children undergoing surgical correction of congenital heart defects, the postoperative level of plasma ET-1 is increased significantly in patients with concomitant pulmonary hypertension compared with those without. ${ }^{6,7}$ Reducing the plasma ET-1 level with modified ultrafiltration has been shown to reduce the incidence of postoperative pulmonary hypertension in these patients, facilitating improved postoperative recovery. ${ }^{9}$

Oxygen-free radicals (OFRs) have been reported to mediate coronary endothelial dysfunction in vitro ${ }^{10}$ and after CPB in humans. ${ }^{11}$ A recent study has shown that significant systemic production of free radicals occurs after initiation of $\mathrm{CPB}$ and persists during early reperfusion. ${ }^{12} \mathrm{~A}$ link between free radical generation and vasoactive mediator production has been identified. ${ }^{13}$ Oxidative stress has been reported to increase ET-1 synthesis in human coronary artery smooth muscle cells. ${ }^{14}$ It is unknown, however, whether antioxidant intervention can effectively reduce postoperative plasma ET-1 formation, attenuate the imbalance of PGI2 and TXA2 production seen after operations with $\mathrm{CPB},{ }^{15,16}$ and improve clinical outcomes in this clinical setting.

Salvia miltiorrhiza (SM), an herb extract containing phenolic compounds such as salvianolic acid A (Figure 1), has been shown to be a potent free-radical scavenger. ${ }^{17,18} \mathrm{We}$ applied SM injection (SMI), a novel approach to antioxidant therapy, during cardiac surgery in patients with congenital heart defects and pulmonary hypertension.

\section{Patients and Methods}

\section{Patient Selection}

Permission to conduct this study was given by the ethics committee of the Renmin Hospital, Wuhan, China. Twenty children (aged 2-15 years old) with mild pulmonary hypertension (mean pulmonary pressure to mean systemic arterial pressure 0.31-0.43) scheduled for operative repair of congenital ventricular or atrial septum defect (ventriculoseptal defect or atrial septic defect) were enrolled in this double-blind randomized study. Primary assessment of pulmonary hypertension was based on clinical, radiographic, and echocardiographic evidence of high pulmonary flow. Patients' absolute pulmonary pressure was measured directly intraoperatively before CPB. Systemic arterial blood pressure was measured by radial artery catheterization. Patients did not take antioxidant vitamins (vitamin $\mathrm{C}$ and $\mathrm{E}$ ) or the cyclooxygenase inhibitor indomethacin before the operation.

\section{Anesthesia and Surgical Management}

Anesthesia was induced with intravenous infusion of midazolam and fentanyl with muscle relaxant pancuronium, and maintained with fentanyl $(40 \mu \mathrm{g} / \mathrm{kg})$ and bolus midazolam when appropriate. Patients were ventilated with oxygen $\mathrm{FIO}_{2}=1.0$ during the procedure. After systemic heparinization, extracorporeal circulation was instituted at a perfusion flow rate of 2.2 to $2.6 \mathrm{~L} / \mathrm{m}^{2}$ per minute with moderate hypothermia $\left(28^{\circ} \mathrm{C}-26^{\circ} \mathrm{C}\right.$ of the rectal temperature).

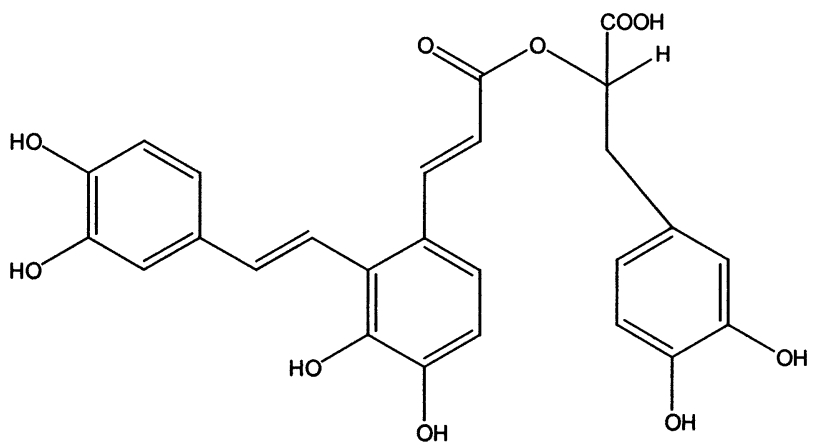

Figure 1. Chemical structure of salvianolic acid A isolated from Salvia miltiorrhiza.

Cardiac asystole was achieved with intermittent multiple-dose cold St Thomas' Hospital cardioplegic solution after continuous application of the aortic crossclamp. Patients' hematocrit values were maintained between $20 \%$ and $26 \%$ during and after the operation, with packed red cells and crystalloid or colloid solution to supplement circulating blood volume. Postoperative inotropic support was defined as the use of dopamine $\left(\geq 5 \mu \mathrm{g} \cdot \mathrm{kg}^{-1} \cdot \min ^{-1}\right.$ with or without concomitant application of epinephrine (0.01-0.02 $\mu \mathrm{g}$. $\mathrm{kg} \cdot \mathrm{min}$ ) for a duration of 30 minutes or longer during the first 12 hours postoperatively. The indication for inotrope administration was a mean radial arterial blood pressure less than $60 \mathrm{~mm} \mathrm{Hg}$.

\section{Experimental Protocol}

Eligible patients were randomized to 2 groups after anesthesia induction and before surgery to group A (control =10) or group B (treatment $=10)$.

The study drug (SMI; 1 g SM per milliliter, Xingang Pharmaceutical Company, Shanghai, China) was diluted in $50 \mathrm{~mL}$ of Ringer's solution immediately before application. Group B patients received SMI $(100 \mathrm{mg} / \mathrm{kg}$ bolus then $100 \mathrm{mg} / \mathrm{kg}$ continuous infusion) at 2 time intervals: (1) preischemia, after anesthetic induction until the initiation of $\mathrm{CPB}$, and (2) ischemia-reperfusion, at the initiation of rewarming until 30 minutes after aortic declamping. The total dosage of SM applied to patients in group B was $400 \mathrm{mg} / \mathrm{kg}$. Patients in group A received equal volumes of Ringer's solution placebo.

Blood samples were taken from a central venous cannulation at 7 time points: post-anesthesia induction $\left(\mathrm{T}_{0}\right), 10$ minutes $\left(\mathrm{T}_{1}\right)$ and 30 minutes $\left(\mathrm{T}_{2}\right)$ after the onset of CPB, 10 minutes $\left(\mathrm{T}_{3}\right)$ and 30 minutes $\left(\mathrm{T}_{4}\right)$ after aortic declamping (myocardial reperfusion), and 30 minutes $\left(\mathrm{T}_{5}\right)$ and 24 hours $\left(\mathrm{T}_{6}\right)$ after termination of CPB.

Blood samples were collected in duplicate. One part of the blood samples was processed on the same day for superoxide dismutase (SOD), lactate dehydrogenase (LDH), and myocardialspecific creatine kinase (CK)-MB activities and the lipid peroxidation product malondialdehyde (MDA) content. Another part of the blood samples was immediately centrifuged, and the plasma was frozen at $-70^{\circ} \mathrm{C}$ and stored until assayed for TXB2, 6-keto$\mathrm{PGF}_{1 \alpha}$ (stable metabolites of TXA2 and PGI2, respectively), and ET-1. 
TABLE 1. Patient profile and perioperative data

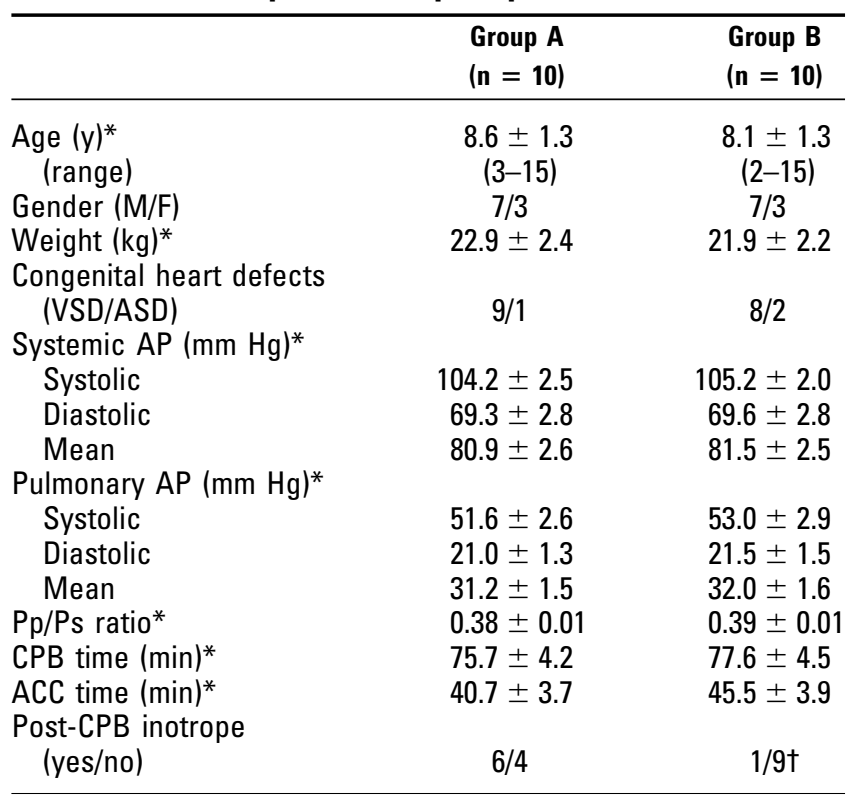

$\overline{A P}$, Arterial pressure; $P p$, mean pulmonary pressure; $P S$, mean systemic pressure; $C P B$, cardiopulmonary bypass; $A C C$, aortic crossclamping; $V S D$, ventricular septal defect; $A S D$, atrial septal defect.

${ }^{*}$ Mean \pm SEM.

$\dagger P<.05$ vs group $\mathrm{A}$ ( $\chi^{2}$ test).

\section{Bioassays}

SOD, MDA, LDH, and CK-MB were measured by chemical analysis (commercial kits; Nanjing Jiangzheng Biological Engine Institute, Nanjing, China). ET-1, 6-keto- $\mathrm{PGF}_{1 \alpha}$, and TXB2 were measured by radioimmunoasay using specific monoclonal antibodies (commercial kits; Thromboxane Research Institute, Shuzhou Medical College, Shuzhou, China). The samples were coded, and the investigators were blinded with respect to patient group.

\section{Statistical Analysis}

All continuous data were expressed as mean \pm SEM. Statistical evaluation of patients' files and perioperative data was performed with an unpaired Student $t$ test or $\chi^{2}$ test when appropriate. Between groups and within group differences of bioassay data were analyzed using 2-way analysis of variance with repeated measures and Bonferroni's corrections (GraphPad Prism, GraphPad Software, San Diego, Calif) when appropriate. Correlations were evaluated with the Pearson test.

\section{Results}

\section{Patient Profile and Perioperative Data}

Patient demographic and operative data are presented in Table 1. Patients were similar in terms of age, diagnosis, preoperative systemic arterial pressure, mean pulmonary pressure to mean systemic arterial pressure ratio, and duration of CPB and aortic crossclamping. Six patients in group A (6/10) needed postoperative inotropic support compared with 1 patient in group B $(1 / 10)(P<.05)$. The duration for inotrope use was 2 hours for the patient in group B. Two patients in group A needed continued postoperative inotropic support for up to 9 and 20 hours, respectively. There was no echocardiographic evidence of residual defect in patients who needed postoperative inotropic support in both groups. The postoperative duration of mechanical ventilation was significantly shorter in group B $(3.7 \pm 0.5$ hours, mean \pm SEM, range 1.5-5.3 hours) than in group A (6.0 \pm 0.8 hours, range 2.5-11 hours) $(P=.03)$. The duration of postoperative hospital stay did not differ between groups ( $P$ $>$.05). Most patients were discharged within 2 weeks postoperatively. One patient in group A was discharged after 3 weeks because of pulmonary complications.

\section{Plasma Levels of MDA and SOD}

Preoperative levels of MDA and SOD (Figure 2) did not differ between groups. MDA in group A increased significantly at 10 minutes after the onset of CPB $\left(\mathrm{T}_{1}\right)$, continued to increase, and remained significantly different from MDA in group $\mathrm{B}$ at all time intervals $(P<.001)$. MDA in group $B$ did not change during $\mathrm{CPB}$ and reperfusion. SOD activity decreased significantly in group A during myocardial ischemia $\left(T_{2}\right)$. This decrease did not occur until 10 minutes of reperfusion $\left(T_{3}\right)$ in group B. SOD levels in group B were significantly higher than in group A at 24 hours $\left(\mathrm{T}_{6}\right)$.

\section{Plasma Levels of LDH and CK-MB Activity}

Baseline levels of LDH and CK-MB (Figure 2) did not differ between groups. The level of LDH in group A increased significantly at 10 minutes after the onset of CPB $\left(\mathrm{T}_{1}\right)$ and was significantly higher than LDH in group $\mathrm{B}$ during ischemia $\left(\mathrm{T}_{2}\right)$ and early reperfusion $\left(\mathrm{T}_{3}\right)$, and at 24 hours $\left(\mathrm{T}_{6}\right)(P<.05)$. LDH initially decreased and did not increase significantly above baseline until 30 minutes of reperfusion $\left(\mathrm{T}_{4}\right)$ in group $\mathrm{B}$. CK-MB increased significantly after reperfusion in both groups and peaked at 30 minutes after CPB $\left(\mathrm{T}_{5}\right)$. It was, however, significantly lower in group $\mathrm{B}$, compared with group $\mathrm{A}$, at $\mathrm{T}_{5}(P<.05$, Figure 2 , $D)$.

\section{Plasma Levels of 6-Keto-PGF $1 \alpha$, TXB2, and Their Ratio}

6-keto-PGF ${ }_{1 \alpha}, \mathrm{TXB} 2$, and their ratio (Figure 3) did not differ between groups at baseline. 6-keto-PGF ${ }_{1 \alpha}$ increased significantly during $\mathrm{CPB}$ in both groups and peaked at 30 minutes during CPB $\left(\mathrm{T}_{2}\right)$ in group $\mathrm{A}$ and at 10 minutes of reperfusion $\left(T_{3}\right)$ in group $B$. It decreased gradually thereafter, but 6-keto-PGF ${ }_{1 \alpha}$ in group A remained significantly higher than in group $B$ at 24 hours $\left(\mathrm{T}_{6}\right)$. In a similar manner, TXB2 increased during CPB in both groups and peaked at 30 minutes during CPB $\left(\mathrm{T}_{2}\right)$. TXB2 in group A remained significantly elevated during reperfusion and returned to baseline at 24 hours $\left(\mathrm{T}_{6}\right)$. TXB2 decreased significantly at 30 minutes of reperfusion $\left(\mathrm{T}_{4}\right)$ and remained below baseline 

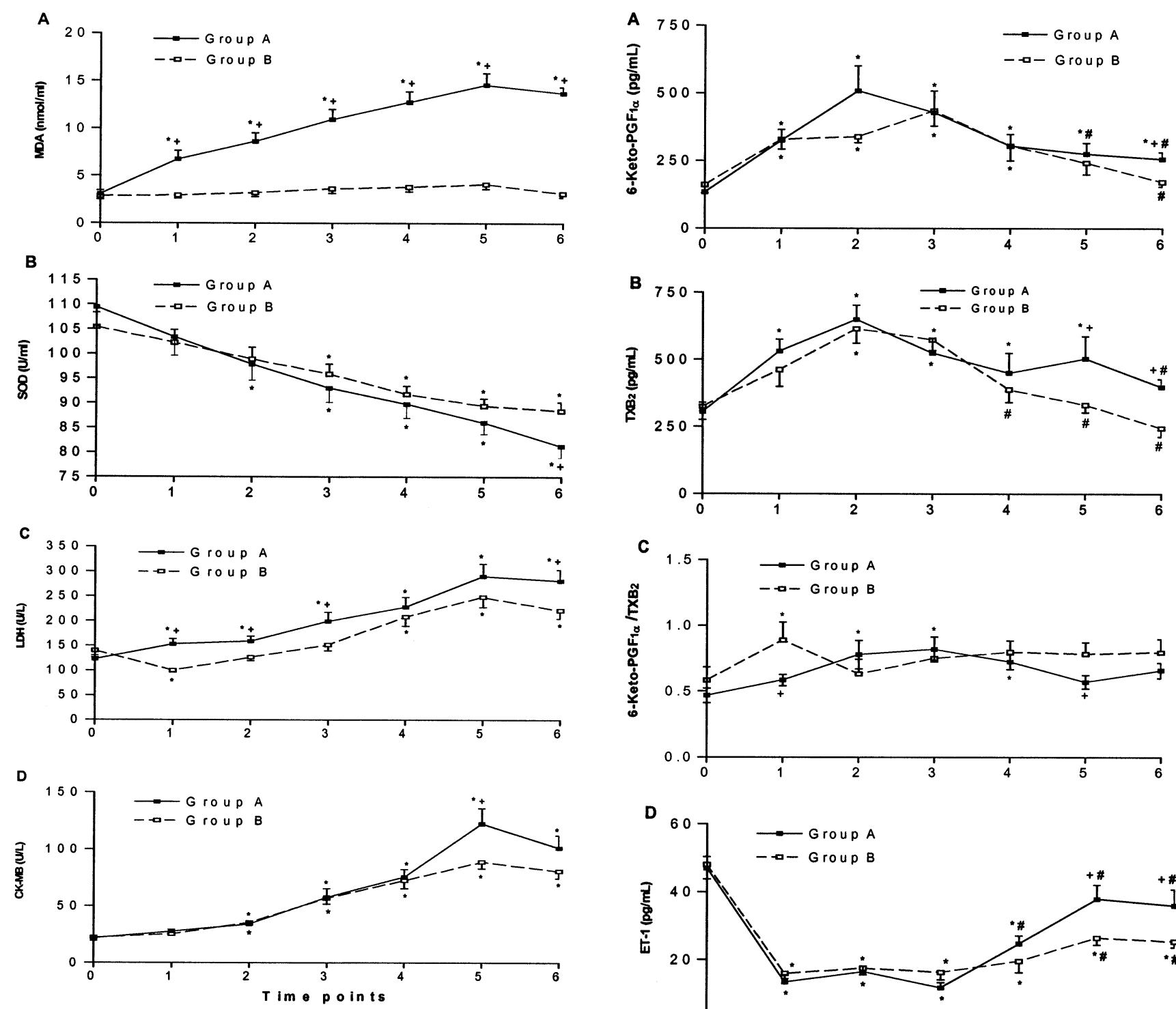

Figure 2. A-D, Variations of perioperative plasma levels of malondialdehyde (MDA) content, superoxide dismutase (SOD), lactate dehydrogenase (LDH), and creatine kinase (CK)-MB activities. The time points $0,1,2,3,4,5$, and 6 represent baseline $\left(T_{0}\right)$, $10\left(T_{1}\right)$ and $30\left(T_{2}\right)$ minutes after the onset of CBP, $10\left(T_{3}\right)$ and 30 $\left(T_{4}\right)$ minutes of reperfusion, 30 minutes after stopping CPB $\left(T_{5}\right)$, and 24 hours $\left(\mathrm{T}_{6}\right)$ after operation, respectively. $\left({ }^{*} P<.05\right.$ vs baseline; $+\boldsymbol{P}<.05$ vs group $\mathrm{B}$.)

for up to 24 hours $\left(\mathrm{T}_{6}\right)$ in group $\mathrm{B}(P<.05)$. TXB2 in group $\mathrm{B}$ was significantly lower than TXB2 in group $\mathrm{A}$ at $\mathrm{T}_{5}$ and $\mathrm{T}_{6}$. The 6-keto-PGF ${ }_{1 \alpha} / \mathrm{TXB} 2$ ratio increased significantly at $\mathrm{T}_{2}, \mathrm{~T}_{3}$, and $\mathrm{T}_{4}$ in group $\mathrm{A}$ and returned to baseline levels thereafter. The 6-keto- $\mathrm{PGF}_{1 \alpha} / \mathrm{TXB} 2$ ratio in group $\mathrm{B}$ was significantly higher than in group $\mathrm{A}$ at $\mathrm{T}_{1}$ and $\mathrm{T}_{5}(P<$ $.05)$.

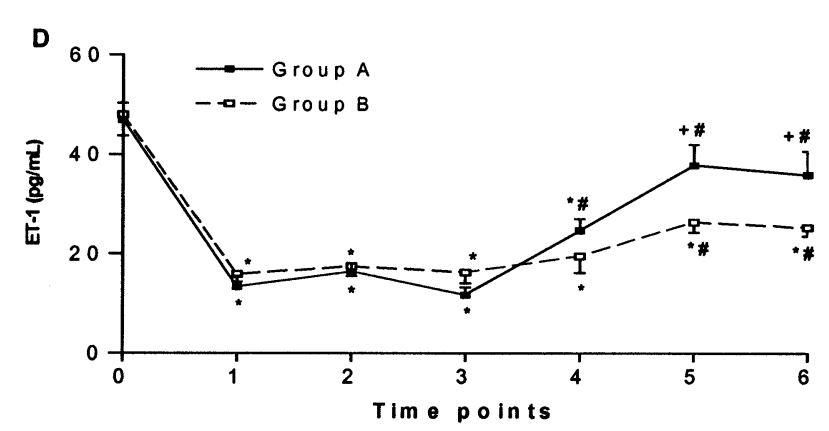

Figure 3. A-D, Variations of perioperative plasma levels of 6-keto-prostaglandin $(P G) F_{1 \alpha}$, thromboxane (TX) $\mathrm{B} 2$, ratio of 6-ketoPGF $_{1 \alpha}$ over TXB2, and endothelin (ET)-1. The time points $0,1,2,3$, 4,5 , and 6 represent baseline $\left(T_{0}\right), 10\left(T_{1}\right)$ and $30\left(T_{2}\right)$ minutes after the onset of $C P B, 10\left(T_{3}\right)$ and $30\left(T_{4}\right)$ minutes of reperfusion, 30 minutes after stopping $C P B\left(T_{5}\right)$, and 24 hours $\left(T_{6}\right)$ after operation, respectively. $\left({ }^{*} P<.05\right.$ vs baseline; $+P<.05$ vs group $B ; \# P<.05$ vs $T_{2}$.)

\section{Plasma Levels of ET-1}

ET-1 decreased significantly during CPB at 10 minutes $\left(\mathrm{T}_{1}\right)$ in both groups (Figure 3,D). ET-1 increased significantly after 30 minutes of reperfusion $\left(\mathrm{T}_{4}\right)$ and peaked at $\mathrm{T}_{5}$ in group A. ET-1 in group B remained significantly lower at 30 


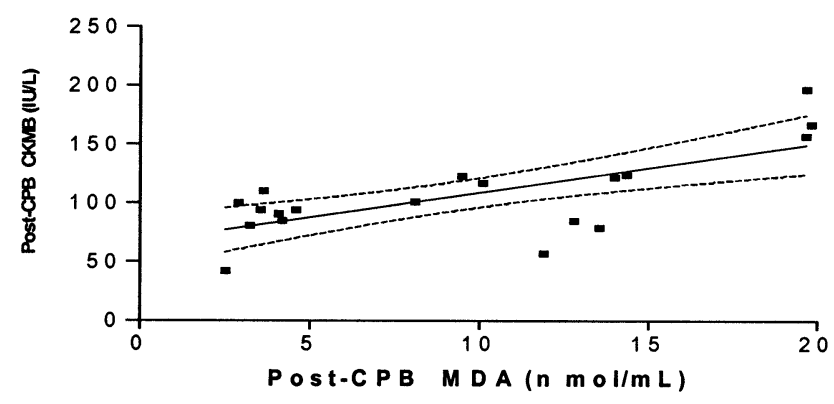

Figure 4. Correlation between plasma MDA and CK-MB activity and ET-1 at 30 minutes post-CPB. Significant correlation exists between MDA and CK-MB ( $r=0.7074,95 \%$ confidence interval: 0.3855-0.8758, $P=.0005) 30$ minutes after completion of CPB.

minutes of reperfusion $\left(\mathrm{T}_{5}\right)$ and 24 hours $\left(\mathrm{T}_{6}\right)$, compared with group A $(P<.05)$.

\section{Correlation Analysis}

Plasma MDA was significantly correlated with CK-MB at 30 minutes after the completion of CPB (CK-MB; $r=0.71$, $P=.0005$, Figure 4). Figure 5 depicts the significant negative correlation between the 6-keto- $\mathrm{PGF}_{1 \alpha} / \mathrm{TXB} 2$ ratio and ET-1 24 hours after operation $(r=-0.64, P=.0025)$.

\section{Discussion}

Our study is the first to investigate the effects of a novel antioxidant therapy on the relationship of systemic lipid peroxidation to plasma levels of ET-1 and the PGI2/TXA2 ratio after cardiac surgery in patients with congenital heart disease and pulmonary hypertension. The major findings include the following: (1) The level of systemic lipid peroxidation after $\mathrm{CPB}$ is significantly correlated with myocardial damage as evidenced by myocardial specific CK-MB, (2) antioxidant therapy results in increased postoperative hemodynamic stability, and (3) the postoperative plasma level of ET-1 is highly negatively correlated with the PGI2/ TXA2 ratio.

Host antioxidants become depleted after CPB.${ }^{19}$ Cellular injury occurs as the result of lipid peroxidation when the production of reactive OFRs exceeds host-defense scavenging capacity. ${ }^{20} \mathrm{~A}$ study has shown that the lipid peroxide concentration in patients undergoing coronary artery bypass grafting with CPB is correlated with the release of cardiac troponin $\mathrm{T}$, a specific marker of myocyte damage, $90 \mathrm{~min}-$ utes after CPB. ${ }^{19}$ This is similar to our finding that lipid peroxidation at 30 minutes after CPB is significantly correlated with myocardial damage (CK-MB) in this pediatric cardiac population.

SM has demonstrated beneficial effects on ischemic disease ${ }^{21}$ and contains several phenolic compounds (eg, salvianolic acids A and B, and danshensu). ${ }^{18}$ Salvianolic acid A

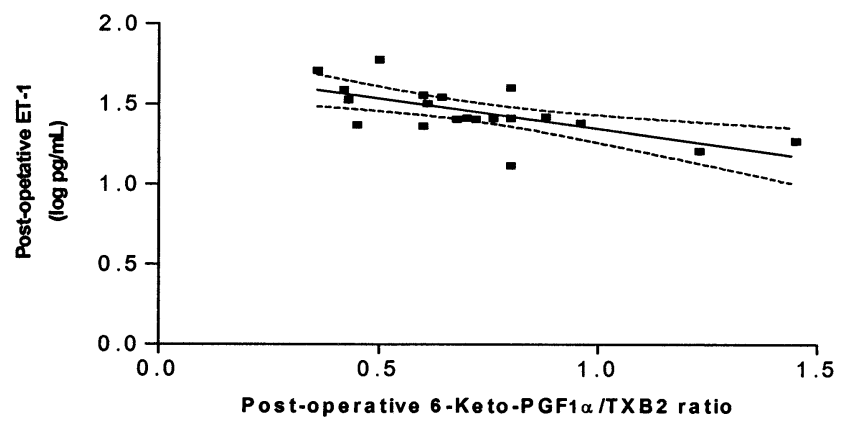

Figure 5. Postoperatively (24 hours), logarithmic plasma ET-1 concentration $(\log \mathrm{pg} / \mathrm{mL})$ was significantly negatively correlated with the ratio of 6-keto- PGF $_{1 \alpha}$ over TXB2 $(r=-0.6373,95 \%$ confidence interval $-0.8423-0.2711, P=.0025)$.

(Figure 1) is the main OFR scavenger. ${ }^{18,22}$ A study using the electron spin resonance trapping technique has found that SM can directly scavenge OFRs generated from the reaction system of xanthine and xanthine oxidase ${ }^{17}$ and protect myocardial mitochondrial membrane from ischemia-reperfusion injury. Treatment with SM in our study prevented the increase of MDA seen in controls during and after CPB. LDH levels decreased significantly at 10 minutes after the onset of CPB $\left(\mathrm{T}_{1}\right)$, and the 6-keto-PGF ${ }_{1 \alpha} / \mathrm{TXB} 2$ ratio increased significantly at the beginning of $\mathrm{CPB}$ in group B. The inability of SM to completely prevent an increase in cardiac enzymes likely reflects a multifactorial cause of postoperative myocardial injury not solely related to OFR generation. An alternative explanation could be that antioxidants, such as the well-known antioxidant vitamins $C$ and $\mathrm{E}$, might be unable to prevent OFR production by other sources despite the inhibition of OFR release from activated polymorphonucleated cells, as recently reported by Wagner and colleagues. ${ }^{23}$ This is, however, not likely the case with $\mathrm{SM}$, which completely prevented the increase of lipid peroxidation in plasma (Figure 2, $A$ ). This is different from the effects of vitamins $\mathrm{C}$ and $\mathrm{E}$, which failed to significantly prevent the increase in OFR release in the whole blood during pulmonary reperfusion. ${ }^{23}$ Our results are in keeping with the protective effects of antioxidant therapy on myocardial ischemia-reperfusion injury seen in previous clinical and laboratory studies. ${ }^{24,25}$ We conclude that SM acts through its OFR scavenger properties.

We measured higher baseline values of ET-1 than did Komai and colleagues. ${ }^{7}$ This discrepancy cannot be completely explained by variation in specificity of the monoclonal antibodies used in each study, despite the fact that ET-1 concentrations detected in the plasma of healthy subjects by different researchers may vary between 0.1 and $48 \mathrm{fmol} / \mathrm{mL}$ $(0.25-120 \mathrm{pg} / \mathrm{mL}) .{ }^{26}$ It may reflect patient differences with respect to age or ethnic origin. The mean age of the patients in Komai's study was 1.6 years. The patients we studied 
were older. We did measure baseline ET-1 values of 19.5 and $28.2 \mathrm{pg} / \mathrm{mL}$ in 2- and 3-year-old patients, respectively. This is comparable to the results of Yoshibayashi and colleagues. ${ }^{27}$ It is possible that ET-1 levels increase as patients with congenital heart defects grow older.

We found that ET-1 significantly increased 30 minutes after terminating CPB. This result is similar to that found by Komai and coworkers, ${ }^{7}$ who observed a significant increase of ET-1 20 minutes after termination of CPB. The finding of a significant decrease in ET-1 during CPB until 10 minutes of reperfusion in our control group is distinct from the work of Komai and colleagues. The precise mechanism for this decrease in ET-1 is uncertain. Hemodilution is an unlikely cause. It may be explained, in part, by Komai and colleagues' use of arterial blood, compared with the central venous blood sampling performed in our study. A difference in arterial and venous ET-1 levels exists during and, particularly, after $\mathrm{CPB} .^{7}$

The increase in PGI2 and TXA2 during CPB that we observed is in keeping with Greeley and colleagues' study. ${ }^{16}$ We identified a tight inverse correlation between the ratio of PGI2/TXA2 and ET-1 concentration 24 hours postoperatively. The precise mechanism is uncertain. Experimental study has shown that PGI2 can inhibit the production and secretion of ET from the cultured endothelial cells, ${ }^{28}$ likely by stimulating particulate guanylate cyclase. ${ }^{29}$ However, we did not find a significant correlation between PGI2 and ET-1 postoperatively. This may indicate that the balance between PGI2 and TXA2 is more important than PGI2 alone in regulating ET-1 in this clinical setting.

Treatment with SM significantly inhibited the increase of TXA2 and enhanced the ratio of PGI2/TXA2 after CPB. This increase in the PGI2/TXA2 ratio seems clinically important because it relates to differences in the inotrope requirements between groups. The endothelium-derived relaxing factor NO and PGI2 are believed to oppose the vasoconstrictor action of ET-1 and TXA2. However, plasma levels of NO have been shown to not change, whereas ET-1 significantly increased after CPB in similar patients. ${ }^{6}$ Thus, the increase in the PGI2/TXA2 ratio becomes an important factor opposing the effects of ET-1 after CPB in this clinical setting.

Adatia and colleagues showed ${ }^{30}$ that the urinary excretion of TXA2 metabolites over PGI2 metabolites was higher in children with a left to right shunt and pulmonary hypertension preoperatively compared with healthy age-matched subjects. The urinary TXA2/PGI2 ratio significantly decreased 12 to 24 hours after successful intracardiac repair and was comparable to the TXA2/PGI2 ratio in the control subjects. ${ }^{30}$ The plasma PGI2/TXA2 ratio increased from $0.46 \pm 0.06$ before operation to $0.66 \pm 0.07$ at 24 hours after successful intracardiac repair in group A in our study (Figure 3,C), which is similar to the finding of Adatia and colleagues. ${ }^{13}$ Our study extends their finding. We observed that the plasma PGI2/TXA2 ratio tends to decrease temporarily during the early phase of reperfusion in the untreated group (group A). SM treatment increased and consistently maintained the plasma PGI2/TXA2 ratio at a relatively higher level. This is of significance, because postoperative myocardial dysfunction occurs primarily during the first several hours after myocardial ischemia and reperfusion.

\section{Conclusion}

We studied 20 pediatric patients with preoperative pulmonary hypertension during surgical correction of congenital heart defects. Antioxidant therapy with SM proved useful in reducing the ET-1 response and was associated with increased postoperative hemodynamic stability. On the basis of our findings, we conclude that an increase in PGI2 or the PGI2/TXA2 ratio influences this process. The latter may inhibit the secretion of ET-1. ${ }^{28,29}$

We acknowledge Drs Taizhong Wang and Dong Li for their support for the bioassays and Ms Xinyun Shi for her assistance. We thank Mr Luigi G. Franciosi for statistical advice, Dr Xing Cheng for helpful advice and discussion, and Dr Richard A. Wall for comments about the molecular structure of salvianolic acid A.

\section{References}

1. Hill GE, Whiteen CW. The role of the vascular endothelium in inflammatory syndromes, atherogenesis, and the propagation disease. J Cardiothorac Vasc Anesth. 1997;11:316-21.

2. Thomas PB, Liu EC, Webb ML, Mukherjee R, Hebbar L, Spinale FG. Exogenous effects and endogenous production of endothelin in cardiac myocytes: potential significance in heart failure. Am J Physiol. 1996; 271(6 Pt 2):H2629-37.

3. Spinale FG, Walker JD, Mukherjee R, Iannini JP, Keever AT, Gallagher KP. Concomitant endothelin receptor subtype-A blockade during the progression of pacing-induced congestive heart failure in rabbits. Beneficial effects on left ventricular and myocyte function. Circulation. 1997;95:1918-29.

4. Bond BR, Dorman BH, Clair MJ, Walker CA, Pinosky ML, Reeves ST, et al. Endothelin-1 during and after cardiopulmonary bypass: association to graft sensitivity and postoperative recovery. $J$ Thorac Cardiovasc Surg. 2001;122:358-64.

5. Joffs C, Walker CA, Hendrick JW, Fary DJ, Almany DK, Davis JN, et al. Endothelin receptor subtype A blockade selectively reduces pulmonary pressure after cardiopulmonary bypass. $J$ Thorac Cardiovasc Surg. 2001;122:365-70.

6. Hiramatsu T, Imai Y, Takanashi Y, Hoshino S, Yashima M, Tanaka SA, et al. Time course of endothelin-1 and nitrate anion levels after cardiopulmonary bypass in congenital heart defects. Ann Thorac Surg. 1997;63:648-52.

7. Komai H, Adatia IT, Elliott MJ, de Leval MR, Haworth SG. Increased plasma levels of endothelin-1 after cardiopulmonary bypass in patients with pulmonary hypertension and congenital heart disease. $J$ Thorac Cardiovasc Surg. 1993;106:473-8.

8. Dorman BH, Bond BR, Clair MJ, Walker CA, Pinosky ML, Reeves ST, et al. Temporal synthesis and release of endothelin within the systemic and myocardial circulation during and after cardiopulmonary bypass: relation to postoperative recovery. $J$ Cardiothorac Vasc Anesth. 2000;14:540-5.

9. Bando K, Vijay P, Turrentine MW, Sharp TG, Means LJ, Ensing GJ, et al. Dilutional and modified ultrafiltration reduces pulmonary hypertension after operations for congenital heart disease: a prospective randomized study. J Thorac Cardiovasc Surg. 1998;115:517-27. 
10. Todoki K, Okabe E, Kiyose T, Sekishita T, Ito H. Oxygen free radical-mediated selective endothelial dysfunction in isolated coronary artery. Am J Physiol. 1992;262(3 Pt 2):H806-12.

11. Sellke FW, Shafique T, Ely DL, Weintraub RM. Coronary endothelial injury after cardiopulmonary bypass and ischemic cardioplegia is mediated by oxygen-derived free radicals. Circulation. 1993;88(5 Pt 2):II395-400.

12. Clermont G, Vergely C, Jazayeri S, Lahet JJ, Goudeau JJ, Lecour S, et al. Systemic free radical activation is a major event involved in myocardial oxidative stress related to cardiopulmonary bypass. Anesthesiology. 2002;96:80-7.

13. Boulanger CM. Secondary endothelial dysfunction: hypertension and heart failure. J Mol Cell Cardiol. 1999;31:39-49.

14. Kahler J, Ewert A, Weckmuller J, Stobbe S, Mittmann C, Koster R, et al. Oxidative stress increases endothelin-1 synthesis in human coronary artery smooth muscle cells. J Cardiovasc Pharmacol. 2001;38: 49-57.

15. Ylikorkala O, Saarela E, Viinikka L. Increased prostacyclin and thromboxane production in man during cardiopulmonary bypass. J Thorac Cardiovasc Surg. 1981;82:245-7.

16. Greeley WJ, Bushman GA, Kong DL, Oldham HN, Peterson MB. Effects of cardiopulmonary bypass on eicosanoid metabolism during pediatric cardiovascular surgery. J Thorac Cardiovasc Surg. 1988;95:842-9.

17. Zhao BL, Jiang W, Zhao Y, Hou JW, Xin WJ. Scavenging effects of Salvia miltiorrhiza on free radicals and its protection for myocardial mitochondrial membranes from ischemia-reperfusion injury. Biochem Mol Biol Int. 1996;38:1171-82.

18. Liu GT, Zhang TM, Wang BE, Wang YW. Protective action of seven natural phenolic compounds against peroxidative damage to biomembranes. Biochem Pharmacol. 1992;43:147-52.

19. McColl AJ, Keeble T, Hadjinikolaou L, Cohen A, Aitkenhead H, Glenville B, et al. Plasma antioxidants: evidence for a protective role against reactive oxygen species following cardiac surgery. Ann Clin Biochem. 1998;35(Pt 5):616-23.

20. Barta E, Pechan I, Cornak V, Luknarova O, Rendekova V, Verchovodko P. Protective effect of alpha-tocopherol and L-ascorbic acid against the ischemic-reperfusion injury in patients during open-heart surgery. Bratisl Lek Listy. 1991;92:174-83.

21. Ji XY, Tan BK, Zhu YZ. Salvia miltiorrhiza and ischemic diseases. Acta Pharmacol Sin. 2000;21:1089-94.

22. Liu P, Hu Y, Liu C, Liu C, Zhu D. Effects of salviainolic acid A (SA-A) on liver injury: SA-A action on hepatic peroxidation. Liver. 2001;21:384-90.

23. Wagner FM, Weber AT, Ploetze K, Schubert F, Pfeiffer S, Albrecht S, et al. Do vitamins $\mathrm{C}$ and $\mathrm{E}$ attenuate the effects of reactive oxygen species during pulmonary reperfusion and thereby prevent injury? Ann Thorac Surg. 2002;74:811-7.

24. Dingchao H, Zhiduan Q, Liye H, Xiaodong F. The protective effects of high-dose ascorbic acid on myocardium against reperfusion injury during and after cardiopulmonary bypass. Thorac Cardiovasc Surg. 1994;42:276-8.

25. Prasad K, Chan WP, Bharadwaj B. Superoxide dismutase and catalase in protection of cardiopulmonary bypass-induced cardiac dysfunction and cellular injury. Can J Cardiol. 1996;12:1083-91.

26. Rossi GP, Seccia TM, Albertin G, Pessina AC. Measurement of endothelin: clinical and research use. Ann Clin Biochem. 2000;37(Pt 5):608-26.

27. Yoshibayashi M, Nishioka K, Nakao K, Saito Y, Matsumura M, Ueda $\mathrm{T}$, et al. Plasma endothelin concentrations in patients with pulmonary hypertension associated with congenital heart defects. Evidence for increased production of endothelin in pulmonary circulation. Circulation. 1991;84:2280-5.

28. Prins BA, Hu RM, Nazario B, Pedram A, Frank HJ, Weber MA, et al. Prostaglandin E2 and prostacyclin inhibit the production and secretion of endothelin from cultured endothelial cells. J Biol Chem. 1994;269: 11938-44.

29. Razandi M, Pedram A, Rubin T, Levin ER. PGE2 and PGI2 inhibit ET-1 secretion from endothelial cells by stimulating particulate guanylate cyclase. Am J Physiol. 1996;270(4 Pt 2):H1342-9.

30. Adatia I, Barrow SE, Stratton PD, Ritter JM, Haworth SG. Effect of intracardiac repair on biosynthesis of thromboxane A2 and prostacyclin in children with a left to right shunt. Br Heart J. 1994;72:452-6. 